\section{Commentary: Early-stage esophageal cancer: The tip of the iceberg}

\section{Thomas Boerner, MD, and Daniela Molena, MD}

The introduction of organ-preserving endoscopic resection has brought a paradigm shift in the treatment of superficial esophageal cancer. For T1a tumors, endoscopic therapy has become the standard of care in many centers, as it is safe and feasible without compromising survival. ${ }^{1}$ Enthusiasm for the procedure has increased its application for more-advanced cancers, ${ }^{2}$ and although it would be ideal to preserve the esophagus in all such patients, endoscopic therapy might not be the best option-even when feasible-to cure disease. T1b tumors penetrating the deep submucosa are associated with a substantial risk of lymph node involvement, ${ }^{3}$ and at present, we lack tools to identify patients with residual disease after endoscopic therapy who would benefit from a more-invasive approach, such as esophagectomy, and/or patients with a high risk of recurrence likely to benefit from adjuvant treatment. We see (and treat) the tip of the iceberg without knowing the more dangerous and aggressive part lies underneath the surface. Until efficient ways to assess residual disease are available, we must rely on pathologic factors that help stratify the risk of nodal involvement, such as tumor size, histologic differentiation, lymphovascular invasion (LVI), and depth of invasion.

Wang and colleagues ${ }^{4}$ reviewed their experience assessing tumor extension to the ductal system of submucosal

From the Thoracic Service, Department of Surgery, Memorial Sloan Kettering Cancer Center, New York, NY.

Dr Molena's work is supported, in part, by the National Institutes of Health/National Cancer Institute Cancer Center Support Grant P30 CA008748.

Disclosures: Dr Molena serves on a steering committee for AstraZeneca and as a consultant for Johnson \& Johnson, Bristol Myers Squibb, Merck, and Genentech; however, these do not represent conflicts of interest with this commentary. Dr Boerner reported no conflicts of interest.

The Journal policy requires editors and reviewers to disclose conflicts of interest and to decline handling or reviewing manuscripts for which they may have a conflict of interest. The editors and reviewers of this article have no conflicts of interest.

Received for publication Sept 15, 2021; revisions received Sept 15, 2021; accepted for publication Sept 15, 2021; available ahead of print Sept 20, 2021.

Address for reprints: Daniela Molena, MD, Thoracic Service, Department of Surgery,

Memorial Sloan Kettering Cancer Center, New York, NY 10065 (E-mail:

molenad@mskcc.org).

J Thorac Cardiovasc Surg 2022;163:1961

$0022-5223 / \$ 36.00$

Copyright (c) 2021 by The American Association for Thoracic Surgery

https://doi.org/10.1016/j.jtcvs.2021.09.027

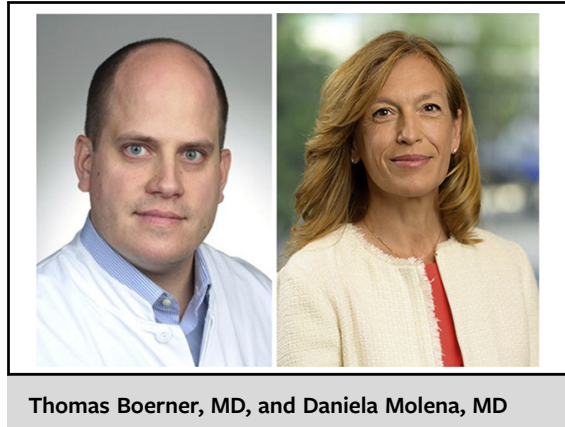

CENTRAL MESSAGE

A retrospective study shows that ductal involvement of submuco-

sal glands is a risk factor for

recurrence in patients with early-

stage esophageal squamous cell

cancer undergoing curative-

intended ESD.

glands in patients undergoing endoscopic submucosal resection (ESD) for superficial squamous carcinoma $(\mathrm{N}=210)$. Their primary aim was to evaluate the clinical impact of ductal involvement (DI) on staging, recurrence, and survival. Presence of DI was observed in $37.1 \%$ of patients and, in addition to LVI, was associated with worse survival. In patients who underwent curative ESD (R0 resection and no deep submucosal invasion or LVI), DI was associated with a greater risk of local recurrence $(12.7 \%$ vs $2.5 \%)$ and was associated with shorter recurrence-free survival (hazard ratio, $4.20 ; P=.038$ ).

We commend the authors for their excellent work and thorough histologic assessment of DI. The study highlights the importance of accurate histologic staging in early-stage esophageal cancer and the unmet need for better stratification criteria in this patient population. Consideration of submucosal glands and their ducts is innovative and potentially adds new information to aid clinical decision-making. A high overall recurrence rate $(37.7 \%)$ was observed in patients with DI after successful ESD, which suggests cancer cells may spread through the intraductal system of the esophageal glands, reaching a deeper depth of invasion than otherwise suspected and potentially leading to residual disease in the glands.

We must be careful, however, when drawing conclusions about the effect of DI. Even though DI was 
independently associated with risk of recurrence, the patient cohort was small, and studies have shown substantial interobserver variability in assessing pathologic risk factors. These findings need validation within larger-scale studies.

Future work should focus on innovative methods to identify patients with residual disease and risk of recurrence after endoscopic therapy. A promising approach might be to use liquid biomarkers, such as circulating tumor DNA, which has shown encouraging results for the detection of residual disease in advanced esophageal cancer after treatment. ${ }^{5}$ It is clear that defining the best therapy for patients with early-stage disease remains challenging and that we urgently need new navigation tools to prevent us from hitting the iceberg.

\section{References}

1. Pech O, May A, Manner H, Behrens A, Pohl J, Weferling M, et al. Long-term efficacy and safety of endoscopic resection for patients with mucosal adenocarcinoma of the esophagus. Gastroenterology. 2014;146:652-60.e651.

2. Merkow RP, Bilimoria KY, Keswani RN, Chung J, Sherman KL, Knab LM, et al Treatment trends, risk of lymph node metastasis, and outcomes for localized esophageal cancer. J Natl Cancer Inst. 2014;106:dju133.

3. Boys JA, Worrell SG, Chandrasoma P, Vallone JG, Maru DM, Zhang L, et al. Can the risk of lymph node metastases be gauged in endoscopically resected submucosal esophageal adenocarcinomas? A multi-center study. J Gastrointest Surg. 2016; 20:6-12.

4. Wang W-L, Chang I-W, Moi S-H, Hsu M-H, Chen C-J, Hsu C-T, et al. Assessment of tumor extension to the ductal system of submucosal glands in patients with superficial esophageal squamous neoplasms: implications for endoscopic resection. J Thorac Cardiovasc Surg. 2022;163:1951-60.e3.

5. Azad TD, Chaudhuri AA, Fang P, Qiao Y, Esfahani MS, Chabon JJ, et al. Circulating tumor DNA analysis for detection of minimal residual disease after chemoradiotherapy for localized esophageal cancer. Gastroenterology. 2020;158: 494-505.e496.
See Article page 1951.

\section{Commentary: Endoscopic treatment is the key for superficial esophageal squamous cell neoplasia}

\author{
Ke-Neng Chen, MD
}

Wang and colleagues ${ }^{1}$ retrospectively reviewed 210 patients with superficial esophageal squamous cell neoplasia (SESCN) who were treated by endoscopic submucosal dissection (ESD) between 2009 and 2017. There were 185 patients who received curative ESD, namely, R0 resection, no deep submucosal invasion, and no lymphovascular invasion. The investigators found that ductal involvement was a

From the Thoracic Surgery Department, Peking University Cancer Hospital, Beijing, China.

Disclosures: The author reported no conflicts of interest.

The Journal policy requires editors and reviewers to disclose conflicts of interest and to decline handling or reviewing manuscripts for which they may have a conflict of interest. The editors and reviewers of this article have no conflicts of interest.

Received for publication Sept 10, 2021; revisions received Sept 10, 2021; accepted for publication Sept 10, 2021; available ahead of print Sept 17, 2021.

Address for reprints: Ke-Neng Chen, MD, Thoracic Surgery Department, Peking University Cancer Hospital, No. 52, Fucheng Rd, Haidian District, Beijing 100142, China (E-mail: chenkeneng@bjmu.edu.cn).

J Thorac Cardiovasc Surg 2022;163:1962-4

$0022-5223 / \$ 36.00$

Copyright (c) 2021 by The American Association for Thoracic Surgery

https://doi.org/10.1016/j.jtcvs.2021.09.018
Check for updates

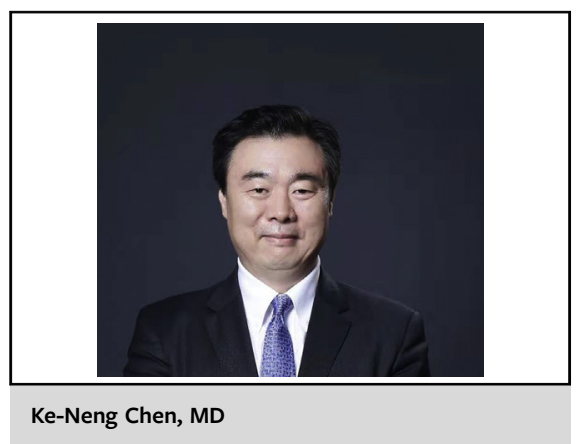

CENTRAL MESSAGE

Traditional esophagectomy

should be selected carefully for

superficial esophageal cancer.

Thorough examinations and full

multidisciplinary discussion

should be performed to select

appropriate patients.

poor prognostic factor for patients with SESCN treated by ESD. I strongly support ESD treatment for SESCN.

\section{A BRIEF HISTORY OF TREATMENT FOR EARLY ESOPHAGEAL CANCER}

Traditional esophagectomy has a 100-year history, and it has been the principal treatment for superficial esophageal 